\title{
Investigation of cutting force oscillations when high productivity milling
}

\author{
Dmitry Aleynikov ${ }^{1}$, Anatoly Lukyanov ${ }^{1}$, Andrey Savilov ${ }^{1, *}$, and Dmitry Paikin ${ }^{1}$ \\ ${ }^{1}$ Irkutsk National Research Technical University, 664074, Irkutsk, Russia
}

\begin{abstract}
The article analyzes cutting force oscillations of highproductivity milling. Based on end-milling experiments using a milling machine tool, characteristics of spatial oscillations of cutting forces were identified. The data analysis using software and oscillation theory methods showed that at high spindle rotation frequencies under certain milling conditions, interaction of the cutting edges and the workpiece is not uniform which deteriorates the machined surface. As the spindle rotation frequency increases due to resonances in the tool and spindle and mutual oscillations of the workpiece and the tool, the cutting force spectrum varies. Some extra harmonic components appear. They index the failure of interaction of the cutting edges and the workpiece.
\end{abstract}

\section{Introduction}

Milling as a technological process is characterized by discontinuous force impacts of the mill on the workpiece $[1,2]$. It causes regular cutting force oscillations $\mathrm{P}(\mathrm{t})$ with a gear mesh frequency of $f_{z}=n_{1} \cdot z / 60=z \cdot f_{1}$ where $n_{1}$ is the angular speed of mill rotation $(r p m) ; z$ is the number of mill teeth; $f_{1}$ is the rotational frequency $(\mathrm{Hz})$. These regular interferences cause forced oscillations of the mill, spindle, tool and workpiece. Mill and workpiece oscillations influence the cutting force. During the high-productivity milling process, resonances and spatial oscillations of the mechanical structure and machine unit occur. They influence the dynamic characteristics of the machine and milling quality [2]. Cutting vibrations also decrease the machine tool resistance. One more negative vibration effect is milling performance degradation due to limited cutting modes.

A set of researches deal with cutting forces during the milling process [3-8]. Their authors develop mathematical models for end milling process simulation. Models describing deformation in cutting found wide application $[1,8,9,11]$. Along with design and geometry parameters of cutting tools, they take into account material properties. For example, some researchers suggest using cutting force ratios $[1,8,11]$. Orthogonal cutting experiments are carried out to determine their values.

Most researches deal with monolithic end mills made from hard material or high-speed steel [4-7]. A smaller number of works deal with end mills with inserts [8] due to a simpler description of design and geometry parameters of monolithic tools. The fact that the tool body and inserts are made from different materials with different mechanical properties

\footnotetext{
* Corresponding author: $\underline{\text { saw@istu.irk.ru }}$
} 
influences the dynamics of cutting. It makes the mathematical process model more complex.

Despite the type of mills, the adequacy of developed mathematical models can be tested. It should be taken into account that in the aircraft industry, high-productivity milling is characterizing by a large volume of chip and is performed with values $a_{e}$, which can be equal to the cutting diameter of the tool $\mathrm{D}_{\mathrm{c}}[7,8]$. Most researchers prefer milling with a small radial cutting depth $\mathrm{a}_{e}[9,10]$ due to better chip formation control and capacitive constraints, particularly power and a spindle torque. Thus, experimental studies approving the milling process under conditions which are most closely approximate the real manufacturing ones are relevant.

\section{Material and method}

The experiments were carried out using DMG HSC 75V Linear Milling Machine Center. The machine has a high-speed spindle with a maximum rotation speed of $\mathrm{N}=28000 \mathrm{rpm}$. Cutting forces were measured with Kistler 9253B23 which can measure three special force components $F_{x}, F_{y}, F_{z}$ (Fig.1). Technical data of the dynamometer platform are presented in Table 1. Deformable aluminum alloy $1933 \mathrm{~T} 2$ consisting of Al-89\%, Zn-7\%, Mg-2\%, $\mathrm{Cu}-1 \%, \mathrm{Zn}-0.15 \%$ was used for machining. The samples were $400 \times 300 \times 50 \mathrm{~mm}$ in size.

A R790-025HA06S2-16L mill with R790-160408PH-NL H13A inserts was used for milling (Fig. 2).

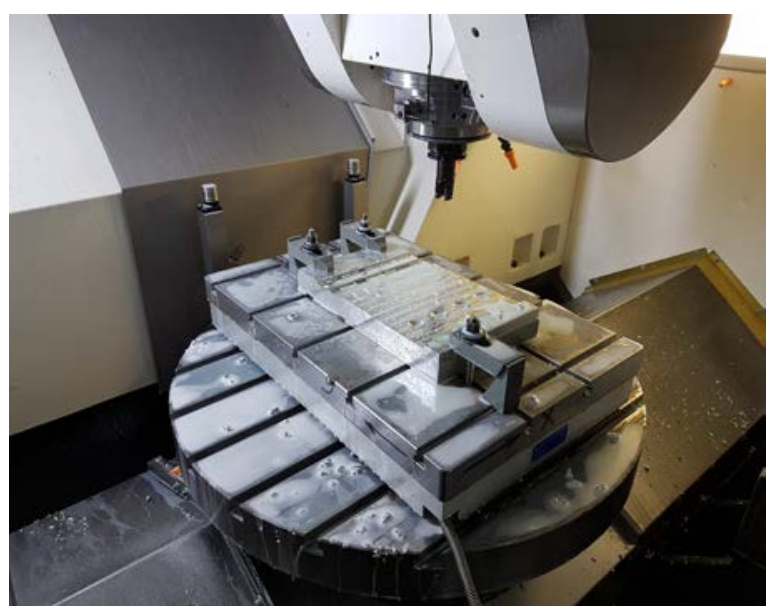

Fig. 1. The working zone of DMG HSC 75V Linear with Kistler type 9253B23 dynamometer

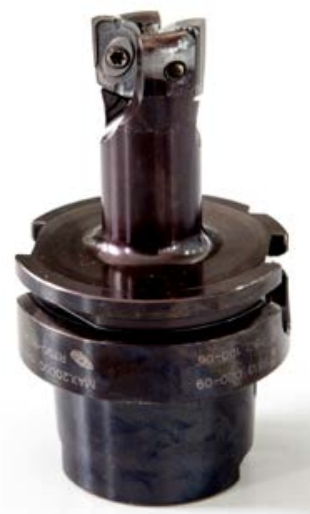

Fig. 2. R790-025HA06S2-16L mill with R790-160408PH-NL H13A inserts

Table 1. Kistler type 9253B23 dynamometer data

\begin{tabular}{|c|c|c|}
\hline Technical data & Type & $\mathbf{9 2 5 3 B 2 3}$ \\
\hline \multicolumn{3}{|c|}{ Calibrated measuring range } \\
\hline $\mathrm{F}_{\mathrm{x}}, \mathrm{F}_{\mathrm{y}}$ & $\mathrm{kN}$ & $0 \ldots 12$ \\
\hline $\mathrm{F}_{\mathrm{z}}$ & $\mathrm{kN}$ & $0 \ldots 25$ \\
\hline \multicolumn{3}{|c|}{ Natural frequency } \\
\hline $\mathrm{fn}(\mathrm{x})$ & $\mathrm{Hz}$ & $\approx 610$ \\
\hline $\mathrm{fn}(\mathrm{y})$ & $\mathrm{Hz}$ & $\approx 570$ \\
\hline $\mathrm{fn}(\mathrm{z})$ & $\mathrm{Hz}$ & $\approx 570$ \\
\hline Weight & $\mathrm{kg}$ & 85 \\
\hline
\end{tabular}


To specify cutting data, modal analysis of the tooling set-up was carried out $[1,11,12]$. Its results and stability lobes are presented in Figure 3.

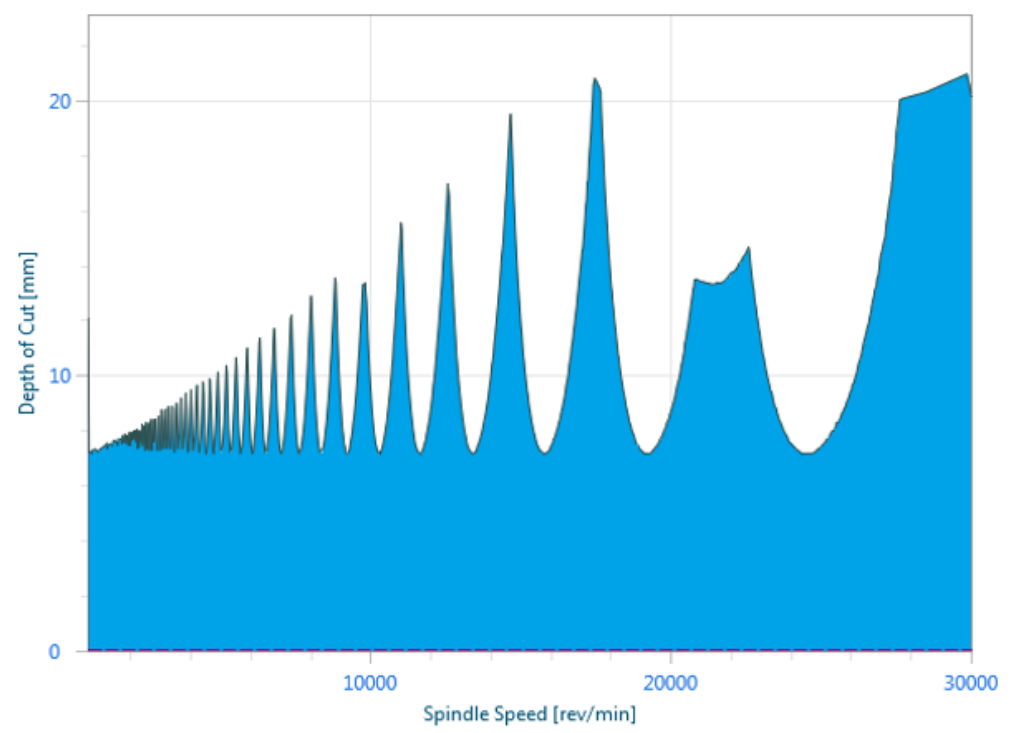

Fig. 3. Stability lobes for R790-025HA06S2-16L mill with R790-160408PH-NL H13A inserts

Based on the modal analysis results, the following cutting data were specified: $V_{c}-$ cutting speed, $a_{p}$ - axial cutting depth, $a_{e}$ - radial cutting depth, $\mathrm{f}_{\mathrm{z}}-$ feed per tooth, $\mathrm{n}_{1}-$ spindle rotation frequency. All these data as well as typical cutting force frequencies and amplitudes on harmonics of rotational $\mathrm{Af}_{1}$ and gear mesh $\mathrm{Af}_{\mathrm{z}}$ frequencies are presented in Table 2.

Table 2. Milling conditions and modal analysis results

\begin{tabular}{ccccccccc}
\hline No & $\begin{array}{c}\mathrm{V}_{\mathrm{c}}, \\
\mathrm{m} / \mathrm{min}\end{array}$ & $\begin{array}{c}\mathrm{a}_{\mathrm{p}}, \\
\mathrm{mm}\end{array}$ & $\begin{array}{c}\mathrm{a}_{\mathrm{e}}, \\
\mathrm{mm}\end{array}$ & $\begin{array}{c}\mathrm{f}_{\mathrm{z}}, \\
\mathrm{mm} / \text { tooth }\end{array}$ & $\mathrm{n}_{1}, \mathrm{rpm}$ & $\begin{array}{c}f_{1}, \\
\mathrm{~Hz}\end{array}$ & $\begin{array}{c}\mathrm{Af}_{1}, \\
\mathrm{~N}\end{array}$ & $\mathrm{Af}_{\mathrm{z}}, \mathrm{N}$ \\
\hline 1 & 1000 & 6 & 10 & 0,25 & 12738 & 212,5 & 183 & 222 \\
2 & 1500 & 6 & 10 & 0,25 & 19110 & 318,5 & $\mathbf{4 1}$ & $\mathbf{1 9 8}$ \\
3 & 2000 & 6 & 10 & 0,25 & 25470 & 424,5 & 92 & 34 \\
4 & 2150 & 6 & 5 & 0,25 & 27390 & 456,5 & 101 & 79 \\
5 & 2150 & 6 & 7,5 & 0,25 & 27390 & 456,5 & 114 & 90 \\
6 & 2150 & 6 & 10 & 0,1 & 27390 & 456,5 & $\mathbf{2 7 2}$ & $\mathbf{1 8}$ \\
7 & 2150 & 6 & 10 & 0,2 & 27390 & 456,5 & 274 & 46 \\
8 & 2150 & 6 & 10 & 0,3 & 27390 & 456,5 & 238 & 42 \\
9 & 2150 & 6 & 10 & 0,4 & 27390 & 456,5 & 159 & 48 \\
10 & 2150 & 6 & 10 & 0,25 & 27390 & 456,5 & 139 & 105 \\
11 & 2150 & 6 & 12 & 0,25 & 27390 & 456,5 & 157 & 122 \\
12 & 2150 & 6 & 15 & 0,25 & 27390 & 456,5 & 164 & 129 \\
13 & 2150 & 7 & 10 & 0,25 & 27390 & 456,5 & 206 & 123 \\
14 & 2150 & 8 & 10 & 0,25 & 27390 & 456,5 & 217 & 133 \\
15 & 2150 & 9 & 10 & 0,25 & 27390 & 456,5 & 240 & 143 \\
16 & 2150 & 10 & 10 & 0,25 & 27390 & 456,5 & 297 & 156 \\
\hline
\end{tabular}




\section{Results and discussion}

Figure 4 shows the oscillograms of three milling force projections $F_{x}, F_{y}, F_{z}$ along feed axis $\mathrm{X}$ for measurements 2 and 6 . Figure 5 shows milling force oscillation spectra for the same measurements. During the ideal milling process when cutting edges are loaded evenly, the spectral component at a gear mesh frequency $\mathrm{f}_{\mathrm{z}}$ exceeds significantly the amplitudes of the other harmonics (see the spectrum in Figure 3 for measurement 2). However, the data of 16 measurements processed in DynoWare developed by Kistler (Fig.4) are opposite. Only for measurements 1 and 2, the amplitudes of spectral components at a gear mesh frequency $f_{z}$ exceed the amplitude of spectral peaks at rotational frequency $f_{1}$. In other measurements, the spectral component of the rotational frequency was fundamental (e.g., see Fig. 5 and 6 of the force spectrum for measurement 6 ).

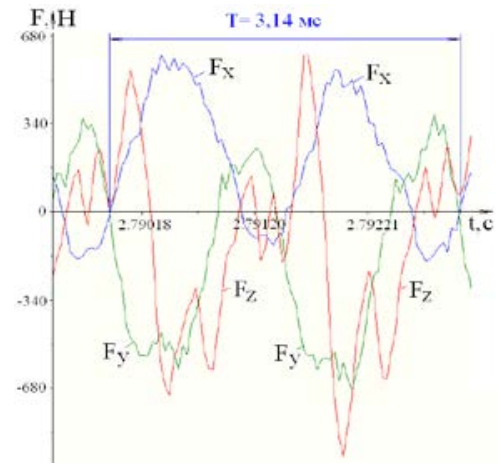

a)

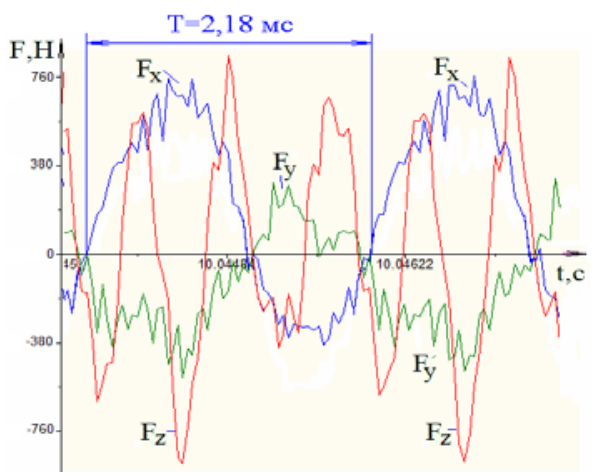

b)

Fig. 4. Oscillograms of the milling force along axes $F_{x}, F_{y}, F_{z}$ for measurements 2 (a) and 6 (b).

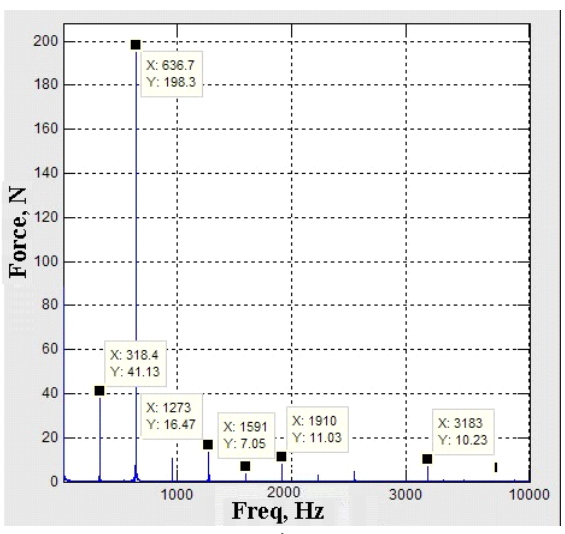

a)

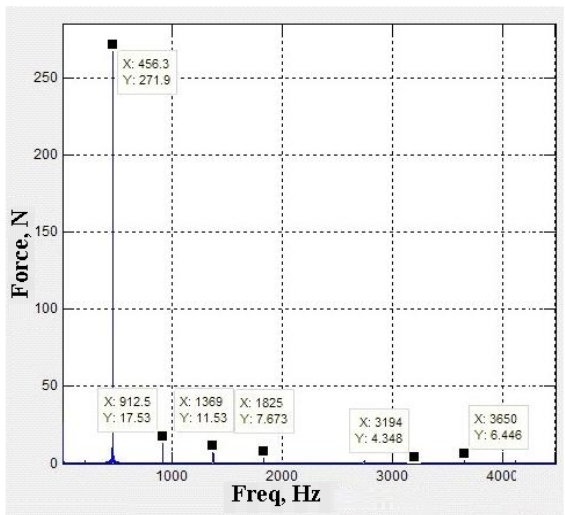

b)

Fig. 5. Milling forces vibration spectra along axis $X$ for measurements 2 (a) and 6 (b).

The spectral analysis data for milling forces can be explained from a resonance perspective. In most experiments, natural frequencies of the dynamometer table are close to rotational and gear mesh frequencies of force excitation. Along with its weight, its piezoelectric sensitive elements form a spatial oscillation system which distorts a signal occurring when milling. Therefore, near-resonant oscillations of the Kistler dynamometer platform were calibrated. Figure 6 shows changes in the amplitudes of the first harmonic of rotational and gear mesh frequencies under varying milling conditions. 


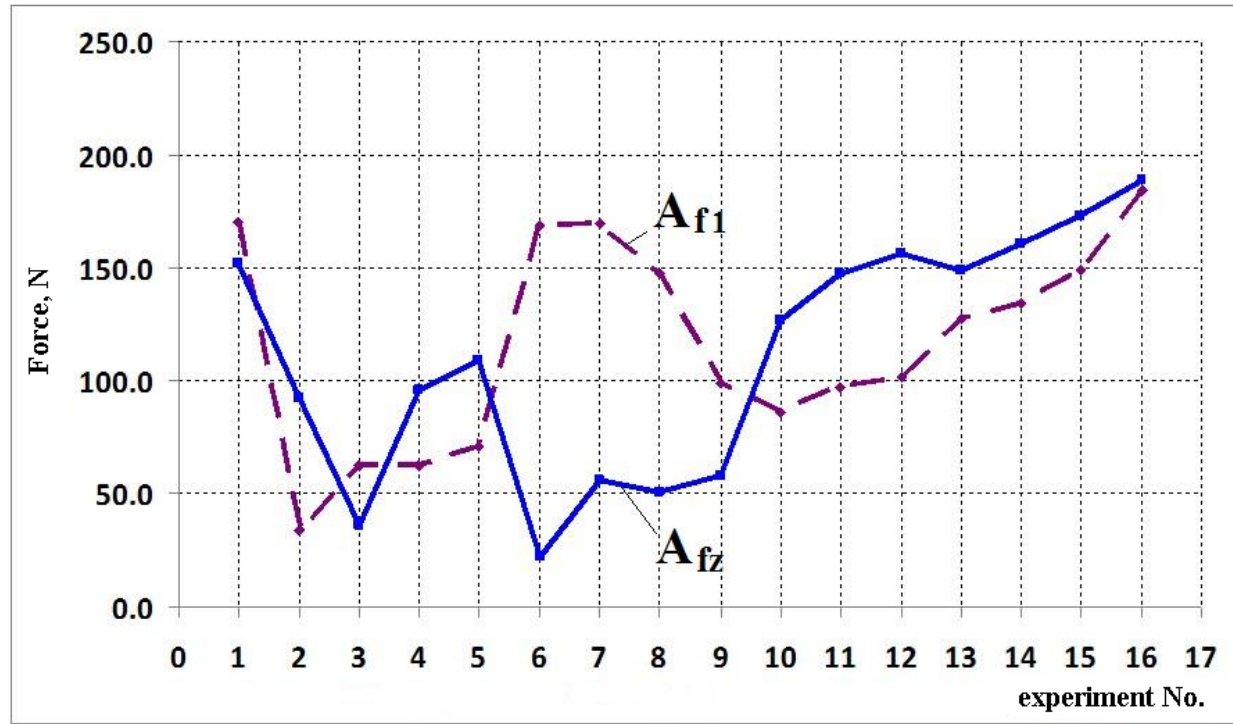

Fig. 6. The curve of varying amplitudes of harmonics of rotational $f_{1}$ and gear mesh $f_{z}$ frequencies after correcting the dynamic error

As can be seen, gear mesh frequency oscillations are not always fundamental. For six measurements $(1,3,6-9)$, fundamental oscillations are at a rotational frequency, i.e. at a spindle and mill frequency. For the other measurements, rotational and gear mesh frequency oscillations are comparable.

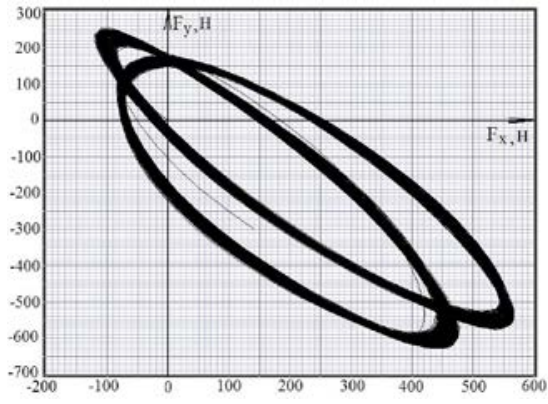

Fig. 7. The orbit of milling forces per $1 \sec (318$ periods of the rotational frequency) for measurement 2

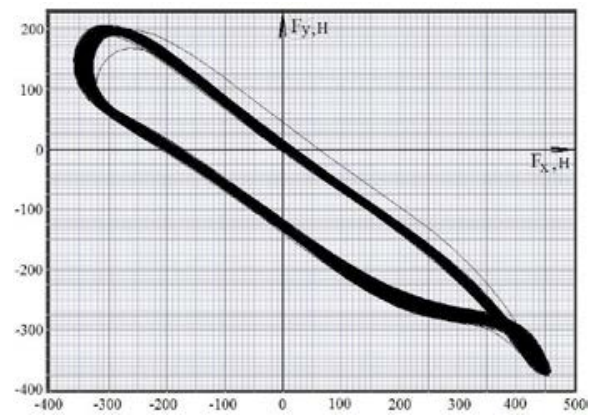

Fig. 8. The orbit of milling forces per $1 \mathrm{sec}$ (458 periods of the rotational frequency) for measurement 6

These conclusions are supported by the diagrams of milling force oscillation orbits in $\mathrm{X}$ and Y (Fig. 7,8). For example, for measurement 2 (Fig. 5) when gear mesh frequency oscillations are fundamental, the orbit corresponds to two closed paths. The orbit of milling forces was determined by processing experimental data using LabView and filtering highfrequency harmonics. The orbit of measurement 2 illustrates an ideal milling process when both cutting edges are loaded evenly and work along the chipping area. For measurement 6 (Fig. 8) when rotational frequency oscillations prevail, the orbit of milling forces per $1 \mathrm{sec}$ measurement corresponds to one closed path. The cutting edges work unevenly. 


\section{Conclusion}

As the spindle rotation frequency increases due to resonances of the technological system, the normal conditions of cutting using two edges get disturbed [13-16]. According to the experimental measurements, the frequency of the first mill oscillations was $6820 \mathrm{~Hz}$. Therefore, excitation oscillations with rotational and gear mesh frequencies within the range of $200 \mathrm{~Hz}$ to $900 \mathrm{~Hz}$ do not influence mill oscillations. Hence, the main factors disturbing the normal milling conditions are resonances of the technological system at high angular spindle rotation speeds.

\section{References}

1. Y. Altintas, Manufacturing Automation: Metal Cutting Mechanics, Machine Tool Vibrations, Cambridge: Cambridge University Press, 2012.

2. Lukyanov A.V., Aleynikov D.P., Portnoy A.Y., Bulletin of Irkutsk State Technical University, 21(4) 30-38 (2017)

3. Kozlov A.M., Kiryuschenko E.V. and Khandozhko A.V., IOP Conference Series: Materials Science and Engineering 177012136 (2017)

4. Wen-Hsiang Lai, Tamkang Journal of Science and Engineering, 3 15-22 (2000)

5. Wu Baohai, Yan Xue, Luo Ming, Gao Ge, Chinese Journal of Aeronautics, 261057 1063 (2013)

6. Takashi Matsumura, Shoichi Tamura, Procedia CIRP 58 566-571 (2017)

7. Min Wan, Wei-Hong Zhang, Jian-Wei Dang, Yun Yang, Applied Mathematical Modelling 34 823-836 (2010)

8. Mark A. Rubeo and Tony L. Schmitz, Procedia Manufacturing, 5 90-105 (2016)

9. U. Karaguzela, M. Bakkal, E. Budak, Procedia CIRP 58 287-292 (2017)

10. Nikolaev A.Yu., IOP Conf. Series: Materials Science and Engineering 177012080 (2017)

11. E. Budak and Y. Altintas, Journal of Dynamic Systems, Measurement, and Control, 120, 10.1115/1.2801317, (1998)

12. Ahmadi K., Altintas Y., Journal of Manufacturing Science and Engineering, 136 (2014)

13. Svinin V.M., Obrabotka metallov/Metall working and material science, 3 28-30 (2005)

14. B. Balachandran, M.X.Zhao, Meccanica, 35 89-109 (2000)

15. Campomanes ML, Altintas Y., Journal of Manufacturing Science and Engineering, 125 (3) 416-422 (2003)

16. Chinesta F., Filice L., Micari F., Rizzuti S. and Umbrello D., International Journal of Material Forming, 1 507-510 (2008) 